Ensaios Historiográficos/ Historiographical Essays

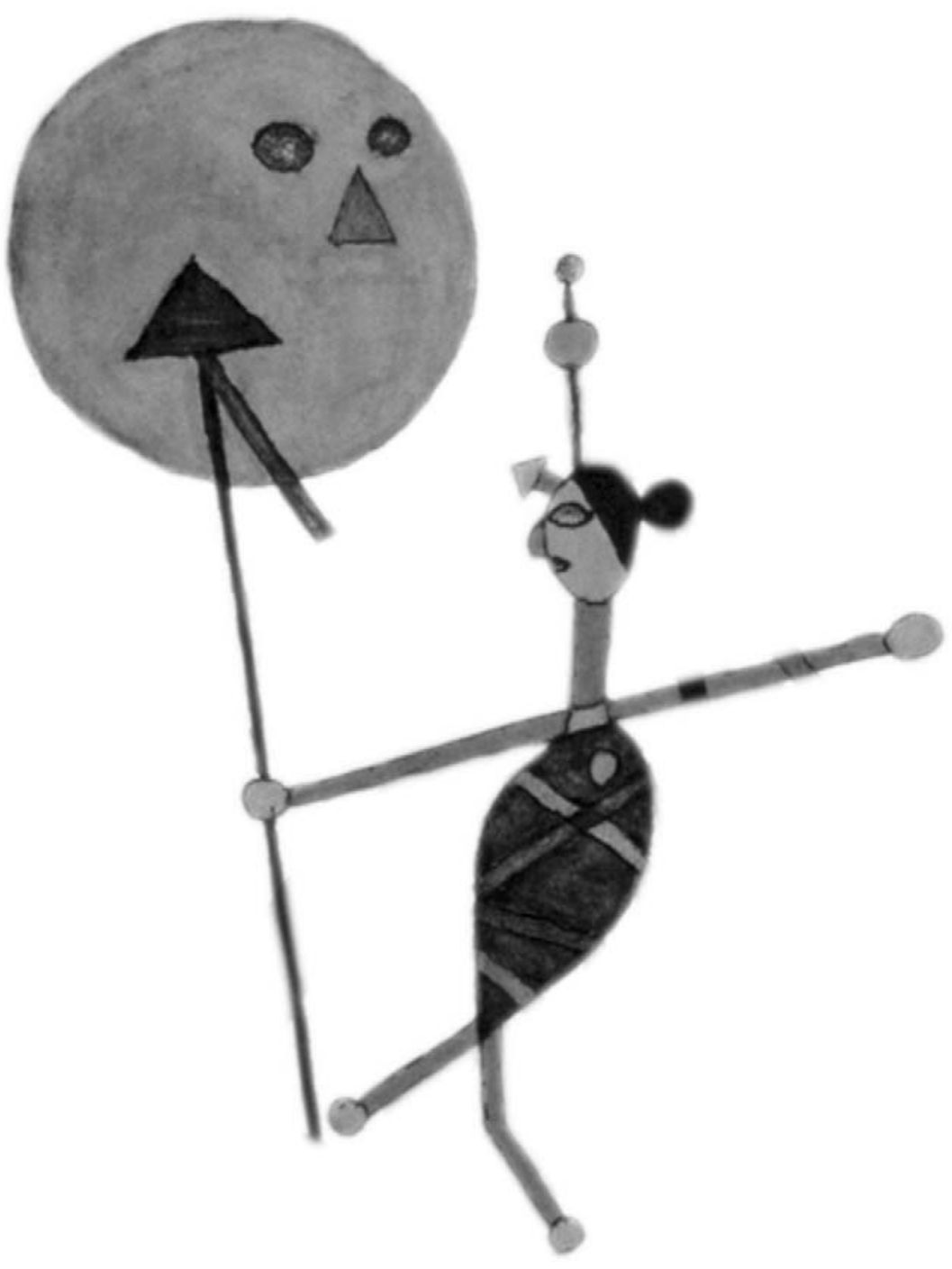




\section{História sem causa? A nova história cultural, a grande narrativa e o dilema pós-colonial}

Barbara WEINSTEIN ${ }^{1}$

RESUMO: Este artigo examina o declínio das grandes narrativas historiográficas norte-americanas, associado ao auge da nova história cultural. A influência da antropologia cultural, com destaque para Clifford Geertz, resultou no privilegiamento da micro-história e no eclipse dos processos de causação e explicação. Ao mesmo tempo, muitos historiadores pós-modernos continuam referendando, ainda que não explicitamente, narrativas eurocêntricas da transição à modernidade. Portanto, as críticas do eurocentrismo - o impulso para "provincializar a Europa" vêm de duas tendências: a nova história mundial, cujos seguidores estão repensando as grandes narrativas, ainda que utilizem métodos históricos bastante tradicionais; e a teoria pós-colonial, com destaque para Dipesh Chakrabarty. Este autor, um crítico incisivo da historiografia eurocêntrica, não consegue oferecer alternativas justamente por rejeitar toda narrativa "historicista". Em contraste, o historiador da África, Steven Feierman, defende a necessidade de reconstruir grandes narrativas, que propiciem pontos de referência e permitam superar o dilema pós-colonial.

PALAVRa S-CHAVE: micro-história; narrativas; período pós-colonial.

O presente artigo não tem por finalidade proceder a um levantamento exaustivo da produção da disciplina história na América do Norte que, para fins deste trabalho, inclui historiadores de todas as áreas, até mesmo historiadores de outras partes do mundo radicados na academia norte-americana. Irei me concentrar em algumas tendências da academia norte-americana e ignorar muitas outras. Afinal, minha perspectiva sobre essa produção intelectual é produto dos meus próprios interesses e preocupações, enquanto historiadora radicada nos Estados 
Unidos, trabalhando numa universidade estadual, em Maryland, mas sempre também (e talvez igualmente) preocupada com as novas tendências históricas na América Latina, especialmente no Brasil. Contudo, tendo em vista os objetivos deste artigo, vou me ater ao meu lado norte-americano e particularmente pretendo discernir posicionamentos recentes, associados ao tema da narrativa, da questão de causas e origens e da condição pós-colonial na produção acadêmica atual.

Também sinto-me obrigada a declarar que não me considero especialista na teoria de história ou meta-história, e certamente estou escrevendo este trabalho mais por causa da minha identidade -aliás ambígua e instável - de historiadora radicada nos Estados Unidos, e menos por minha grande erudição nas questões teóricas. Isto pode me levar a definir categorias ou problemas de uma maneira que alguém mais familiarizado com este tipo de discurso acadêmico possa considerar errada ou, ainda pior, ingênua. Por exemplo, não vou problematizar a relação entre narrativa histórica, causas e origens; vou supor que toda narrativa remete à questão das causas e origens, um pressuposto que uma narratologista poderia considerar profundamente questionável. Espero que fique evidente que essas distinções não são muito produtivas no contexto deste artigo, mas pode ser que, em outros contextos, seja imprescindível separar essas questões. ${ }^{2}$

Tendo em vista essas ressalvas e advertências, vou falar ou melhor, construir uma narrativa ao longo deste artigo, que trata de uma série de mudanças na disciplina histórica ou, mais precisamente, se concentra na forma que estas mudanças assumiram na academia norte-americana. Trata-se de verificar o que estes deslocamentos significavam e significam - para o status da grande narrativa macro-histórica, que saiu de moda com o auge da nova história cultural, mas que está voltando atualmente, embora pela porta dos fundos, com a nova história mundial e a historiografia pós-colonial.

À semelhança do que ocorria no Brasil, o auge da nova história cultural nos Estados Unidos se fez acompanhar por um declínio na produção de pesquisas preocupadas com as origens ou as causas de um evento ou um processo histórico, o que também implicava no declínio 
de uma certa forma de "narrativa explicativa". Hoje em dia é difícil achar um historiador sério e engajado trabalhando, por exemplo, com um tema como "as causas da Revolução Francesa," ou "as causas da guerra civil," ou "as origens do New Deal," ou "o surgimento de relações capitalistas na Nova Inglaterra". Um livro sobre A Guerra Civil e a Memória Americana, por sua vez, é considerado um assunto legítimo (e um livro muito elogiado). ${ }^{3}$ A velha questão das causas não aparece mais, pelo menos de modo explícito.

O quase-apagamento dessas questões, que eram tão candentes na historiografia norte-americana poucas décadas atrás, inclusive durante o apogeu da nova história social, pode ser explicado, em parte, pelo ceticismo dos historiadores atuais quanto às grandes narrativas em geral e, mais especificamente, pela ampla crítica do historiador que se posiciona como narrador onisciente, impondo sua narrativa sobre a desordem ou a multiplicidade da(s) história(s), ignorando ou apagando outras narrativas e outras vozes. Além disso, havia (e há) outras graves considerações. Uma vez que aceitemos que toda narrativa carrega uma série de decisões interpretativas, como poderemos construir uma narrativa coerente que não caia na tentação teleológica? Da mesma forma, se aceitarmos a "instabilidade do sujeito," como poderemos narrar a história dos trabalhadores? Ou das mulheres? Ou dos gays? Todas estas dúvidas e estas críticas plenamente saudáveis, do meu ponto de vista, acabavam desvirtuando, até deslegitimando um certo tipo de narrativa explicativo-historicista, preocupada com causas e origens.

Ainda mais, para quem estava mergulhando na nova história cultural, especialmente quando esta começava a tomar forma, havia também a memória desagradável de um outro tipo de história cultural, com sua tendência a "essencializar" a cultura, tratando-a como o fator determinante para o destino de uma certa coletividade. Era justamente o cheiro de eurocentrismo, e até de racismo, desta velha história cultural - que pressupunha que certas culturas desfrutavam de qualidades que as tornavam aptas para a modernidade, o progresso econômico, a cidadania moderna, e outras não - que levou gerações anteriores a privilegiar a história social e econômica, em detrimento da história 
cultural, e tratar o cultural como sempre redutível ao social e ao material. ${ }^{4}$ Assim, voltar a uma narrativa explicativa e historicista, na qual a cultura sirva como a fundação de explicação, era algo a ser evitado a todo custo.

Entretanto, o historiador não abandonou o seu ofício. Cabe perguntar: o que colocar no lugar desses projetos já ultrapassados? No contexto da academia norte-americana, na hora do viés cultural, talvez a maior influência tenha sido a antropologia e, sobretudo, a obra de Clifford Geertz. Certamente não foi a única e mesmo os historiadores norte-americanos, com sua fama de provincianismo, estavam lendo Foucault, Derrida e Bourdieu, por exemplo. Geertz, com sua "descrição densa", derivada da antropologia simbólica, insistia que toda atividade social transparece dentro de uma rede de significações, e os símbolos/textos devem ser lidos e interpretados no seu próprio contexto, usando a lógica interna do sistema local. Obviamente, a "explicação" fazia parte do projeto geertziano e, nas próprias palavras dele: "vou atrás de explicação, interpretando expressões sociais que são, na sua superfície, enigmáticas”. Ao mesmo tempo, ele fazia uma distinção entre explicação como interpretação e a enumeração de causas gerais: Segundo Geertz, "cultura não é um poder, não é algo ao qual acontecimentos sociais, comportamentos, instituições, ou processos podem ser causalmente atribuídos; é um contexto, algo dentro do qual esses podem ser inteligivelmente — aliás, 'densamente'—descritos."

Uma implicação da ampla adaptação destes métodos antropológicos à pesquisa histórica é o eclipse da preocupação com a "mudança ao longo do tempo" (em inglês, "change over time"), e o surgimento de uma preferência por temáticas sincrônicas em vez de diacrônicas. Fortaleceu-se a tendência para examinar "um pedacinho do tempo," um instante, um "snapshot." A pequena história, por vezes de caráter anedótico, transformou-se na base, por excelência, da análise da nova história cultural. Proliferaram livros e artigos baseados num pequeno episódio_-pequeno mas repleto de significados! Um exemplo fundador e quinta-essencial, porém de natureza transicional, porque ainda meio inocente no tratamento das fontes históricas, foi O Grande Massacre dos 
Gatos, de Robert Darnton. ${ }^{6}$ Para dar um exemplo muito mais recente, quero citar um livro que não li ainda (e provavelmente nunca vou ler), mas o anúncio do livro estava na capa de uma revista que consultei para este trabalho. O nome do livro é O Cálice Envenenado, de Jeffrey Freedman, publicado o ano passado. $\mathrm{O}$ resumo do livro é o seguinte:

[Este livro] relata a história de um caso criminoso por muito tempo esquecido: o envenenamento do vinho sacramental na catedral de Zurich em 1776. Esta história é envolvente e misteriosa, mas também é muito mais do que uma simples boa história. O episódio virou uma cause célèbre, o objeto de um animado debate público que destacava o problema do mal. Traçando os pensamentos e ações dos europeus enquanto eles lutavam para compreender um mau ato incompreensível, este livro traz à luz um evento-chave na história do Iluminismo alemão, durante o qual os iluministas ficavam obrigados a interrogar os limites da própria razão.

Eis o comentário do famoso historiador Anthony Grafton sobre o livro de Freedman: "Esta é uma pequena obra-prima: é a essência destilada da história cultural..."7

Assim, em vez da velha narrativa explicativa, preocupada com causas/origens e conseqüências, passou-se para uma nova narrativa, de curtíssima duração, concentrada num evento que, se bem escolhido, ofereceria um quadro repleto de significados, mas que não se referia a causas ou origens e, em termos de conseqüências, mas, no máximo, o que fazia era indicar, mas não determinar uma nova gama de possibilidades históricas. $\mathrm{O}$ apelo da anedota, além de oferecer uma certa eficiência em termos de pesquisa de arquivo, era duplo: à primeira vista, oferecia um pedaço "puro" da realidade; aliás, na verdade, é mais apropriado pensar na anedota como um pedaço de uma narrativa. E, além disso, a anedota se adequava razoavelmente bem aos métodos da antropologia simbólica. ${ }^{8}$

Isto não quer dizer que todos os seguidores de Clifford Geertz na área de história cultivavam o mesmo terreno. Há vários exemplos que divergiam deste padrão; aqui, vou destacar apenas dois — um que tra- 
ta de uma época que escapa totalmente aos limites da história anedótica, e outro que trata explicitamente da questão de "change over time." O primeiro é o recente livro - imenso e imensamente estimulante de Eric Van Young sobre as revoltas populares na época das guerras de independência no México. Diferentemente da maioria dos trabalhos sobre este tema, inclusive o livro anterior do próprio autor, o objetivo não é explicar as guerras de independência; 0 muito pelo contrário, $\mathrm{o}$ autor recusa-se qualquer "modelo" de explicação, uma vez que este tende a homogeneizar as várias categorias da população colonial que reagiram de maneiras muito diversas à luta contra a Espanha. Em vez de falar de causas, Van Young privilegia as preocupações geertzianas, concentrando-se na questão dos significados culturais das revoltas para seus participantes. Por exemplo, quando os camponeses de uma certa região falavam do rei, o que significava para eles a figura do rei? Entre outras finalidades, ele tenta mostrar (o livro, por sinal, se chama The Other Rebellion) que os grupos subalternos que participavam das revoltas recorreram a uma rede de símbolos, ritos e discursos muito distinta (até o inverso) dos discursos que alimentavam a revolta entre a população dos grupos mais privilegiados (os criollos) contra a Coroa. ${ }^{9}$ Interessante notar que uma das críticas feitas ao livro insiste que Van Young teria exagerado na distância cultural entre as elites e os grupos subalternos. Seus críticos apontam que na documentação do México pós-colonial se encontram comunidades indígenas usando uma linguagem política "moderna", referindo-se a direitos de cidadania ou reivindicando o direito de votar, etc. ${ }^{10} \mathrm{O}$ autor, por seu turno, afirma algo que aparentemente mudou nas duas décadas entre o auge das sublevações populares e a formação do Estado pós-colonial. Enfim, apesar de ter escrito um livro de mais de 700 páginas sobre uma enorme região de intensa turbulência, seu livro também é um "snapshot", ou talvez a melhor imagem seria a de uma planta com raízes muito rasas e ramificações muito abreviadas.

O segundo trabalho nitidamente inspirado na obra de Geertz, mas que foge do padrão da anedota, é um belo artigo de Monique Scheer, publicado na American Historical Review, intitulado Da majestade ao 
mistério: mudanças nos significados das Madonas Pretas do Século XVI ao XIX. ${ }^{11}$ Como o próprio título indica, a autora está preocupada com o change over time. Mas a natureza da preocupação reflete sua imersão nos métodos antropológicos. O objeto do artigo é fascinante: recusando a ocupar-se da questão do porquê essas madonas - um grupo de imagens amplamente conhecidas na Europa desde a época medieval - tinham a cor preta, sob o argumento de que esta questão não passa de uma distração "positivista", e concordo com ela, Monique Scheer prefere investigar os significados atribuídos à cor dessas madonas em épocas diferentes, culminando no século XIX. Noutras palavras, tratase de saber como, em diferentes contextos culturais, comentaristas notavam (ou não), explicavam (ou não) a cor dessas madonas. Ela mostra que, anteriormente ao século XVIII, a tendência era interpretar a cor como um sinal da antigüidade e da autenticidade das imagens, ou, especialmente entre grupos populares, de seus atributos milagrosos. No final do século XVIII, pode-se notar uma mudança expressiva nas percepções das madonas, que deixam de ser estátuas de cor preta e viram imagens de mulher negra ou até africana. Esta transformação na percepção é atribuída por ela a duas grandes mudanças da época. Uma, evidentemente, é a construção de categorias raciais, que levam os comentaristas a associar a cor preta à pele escura, implicando em diferença racial. A outra é a secularização da sociedade européia, que permite os comentaristas a olhar as madonas não como objetos sagrados (e ainda menos milagrosos), mas como obras de arte cuja cor exige uma explicação científica. Neste sentido, as imagens viram um "mistério", mas não no sentido religioso. Os novos comentaristas do século XIX, perplexos com a idéia de uma Maria africana, e por isto "feia" o próprio Karl Marx desprezava a Schwarze Maria numa carta de 1856 à sua mulher - acabaram concluindo que a cor era o resultado de um acidente, isto é, a fumaça das velas nas igrejas e catedrais.

$\mathrm{O}$ artigo demonstra que os métodos de Geertz não são necessariamente incompatíveis com uma consideração de change over time, no sentido literal. Mas é importante reconhecer as dimensões desta pesquisa. ${ }^{12}$ Já no final do texto, a historiadora resume sua contribuição 
em dois níveis. Um, no sentido mais geral, é o de mostrar como certos significados podem ser perdidos ao longo da história, um insight que certamente é importante, mas nada extraordinário. O outro é uma contribuição justamente à história dessas madonas. "Historicizar nossa percepção das madonas pretas, pode ser o primeiro passo necessário para repensar nestas figuras com novas perguntas." ${ }^{13}$ É claro que podemos ler e perceber muito mais na interpretação que ela nos oferece, além da melhor compreensão dessas imagens. Mas o que é especialmente interessante para a finalidade deste trabalho é o fato de a autora se referir à grande narrativa histórica, que fornece os elementos determinantes das mudanças que ela destaca—o surgimento de "raça" como um modo principal de organizar a população humana e a secularização da sociedade européia - como se pudéssemos tratar desta narrativa como um dado nada problemático, que não demanda nem mesmo uma nota de rodapé. Por isso, apesar da minha grande admiração pelo seu artigo, o trabalho da autora exemplifica, do meu ponto de vista, uma das fraquezas que os métodos da antropologia cultural trouxeram para a disciplina história.

Claro que não podemos exigir dessa historiadora uma reinterpretação de toda a narrativa macro-histórica, mas podemos esperar um reconhecimento por parte dela de estar invocando uma narrativa de causação, e de maneira que não deixar margem para problematizar ou questionar os pressupostos dessa narrativa macro-histórica. Hoje seria difícil recorrer a uma narrativa tradicional da história como uma marcha para o progresso, e certamente valorizamos o conceito de rupturas tanto quanto (ou até mais) o conceito de continuidades. Mas isto, a meu ver, não nos permite falar da modernidade, ou da secularização, ou das novas mentalidades, partindo do século XVIII como um simples gerador de significados ou um contexto estável e inquestionável. E é isto que acaba acontecendo dentro de uma abordagem antropológica. A análise de Geertz, por exemplo, pode indicar os meios de simbolização da relação colonial, mas o trabalho dele não nos diz quase nada da história do colonialismo como um processo, como um sistema, como uma relação de poder instável e permanentemente contestado. 
De qualquer forma, há muitos sinais de que esta tendência historiográfica está se esgotando, e por várias razões. A mesma Lynn Hunt que organizou a coletânea agora clássica sobre a nova história cultural (The New Cultural History, 1989), recentemente co-organizou outra que se chama Beyond the Cultural Turn (1999). Lendo os artigos desta antologia, ou da revista History and Theory, percebe-se uma gama de motivos e impulsos para ir "além" dos métodos antropológicos. Há uma consideração de ordem prática - para Geertz e seus seguidores tudo é um texto e, neste sentido, seu método pode ser aplicado da mesma forma a um rito atual testemunhado por um antropólogo, ou um do século XVIII, inscrito num documento da época. Mas a natureza inevitavelmente fragmentária da evidência histórica, os níveis adicionais de mediação entre o evento e o intérprete ou espectador, e a falta de fácil acesso a uma multiplicidade de informantes significa que, raras vezes, a interpretação de um texto situado no passado tem a rique$\mathrm{za}$ e as múltiplas camadas que caracterizam a obra de Geertz. ${ }^{14}$

Ainda mais, pode-se perceber uma vontade (talvez ainda mal articulada) de voltar a uma narrativa mais abrangente, que abra possibilidades de pensar novamente em causas e origens-se não no sentido positivista, com suas leis de causação, pelo menos como um grande evento, da maneira traçada por Chartier, que insiste numa distinção entre causas e origens, no seu Origens Culturais da Revolução Francesa. ${ }^{15}$ É perceptível a nostalgia de uma narrativa macro-histórica que nos permita pensar mais explicitamente nas conseqüências das operações de significação que ocupam tanto espaço nas pesquisas mais recentes. Acho que o debate incessante sobre a possibilidade (ou não) de falar de uma esfera de sociabilidade ou de ação social, que não é redutível à esfera da cultura (um debate que até hoje tem sido muito pouco produtivo), é justamente um sintoma da vontade de escapar dos limites impostos na narrativa histórica pela nova história cultural e pelo pós-modernismo. ${ }^{16}$

Esta linha de crítica, na maior parte implícita, tem muitas ramificações, mas quero dedicar o restante deste artigo a um campo de pesquisa e pedagogia em que a questão da volta a uma narrativa macro- 
histórica é especialmente pertinente: a world history. Esta é uma área disciplinar que pretendo posicionar em relação ao novo campo historiográfico do pós-colonialismo. Obviamente, a noção de história mundial não é uma novidade em si mesma, mas de certa forma estou me referindo a uma "nova história mundial", profundamente marcada pelo momento histórico e historiográfico do seu surgimento. Em primeiro lugar, é importante notar que a história mundial, como ela existe atualmente é, sobretudo, uma área de pedagogia. Ainda existem relativamente poucos historiadores que se classificariam como pesquisadores nesta área. Aliás, uma das críticas comuns desta disciplina é exatamente que ela não reflete o nível de especialização e profissionalização que caracteriza outras áreas disciplinares, e os que são a favor desta nova tendência concordam com a observação, mas não a encaram como problema, muito pelo contrário. Claro que todo projeto de história tem seu aspecto pedagógico, mas neste caso ele é absolutamente explícito. À primeira vista, pode fazer muito sentido o fato deste tipo de curso proliferar neste momento de intensa globalização, porém isto não explica a forma que estes cursos, em geral, estão assumindo. Só é possível entender as dimensões da finalidade pedagógica reconhecendo o que é que estes cursos de história mundial pretendem suplantar e não suplementar. Este venerável curso tem vários nomes - Western Civilization, the Rise of the West - mas, no fundo, tenderia a ser "O Triunfo do Ocidente". A história mundial, na sua forma paradigmática, não é concebida como uma mera "amplificação" do curso de Western Civilization. Sua finalidade é repensar o lugar do Ocidente na narrativa macro-histórica. ${ }^{17}$

Não é preciso que me detenha por muito tempo nas várias críticas a este velho paradigma do Triunfo do Ocidente (e voltarei ao tema no contexto da crítica pós-colonial). Por enquanto, é suficiente citar a famosa anedota, talvez inventada: Um repórter europeu pergunta a Mahatma Gandhi: "O que é que o senhor pensa da civilização ocidental?" E Gandhi responde: "Acho que seria uma boa idéia”. A grande maioria dos historiadores que ensinam nos cursos de World History foi inspirada pelo espírito desta anedota. É evidente que existe uma plu- 
ralidade de estratégias para a finalidade de "decenter" Europa/Ocidente - ou, citando a frase do historiador da escola de estudos subalternos ${ }^{18}$ Dipesh Chakrabarty, para "provincializar a Europa." ${ }^{19}$ E todos eles, por motivos óbvios, envolvem uma narrativa explicativa e macro-histórica. Uma estratégia com implicações políticas bastante claras é insistir que a única vantagem que a Europa levava na concorrência pela hegemonia mundial estava em suas redes de colonização e escravização - sua exploração de outras culturas, muitas vezes mais sofisticadas que ela, mas mal preparadas para as depredações e barbaridades dos europeus. ${ }^{20}$ De certa forma, este argumento é uma inversão do velho discurso da superioridade da Europa por meio da sua ilustração, pensamento livre, comércio livre, disciplina e temperamento científico e secular - um discurso, por sinal, que ainda tem seus grandes defensores. Nos últimos anos, duas prestigiadas figuras da velha história mundial - Alfred Crosby e David Landes, professores de Texas e Harvard - têm publicado livros muito elogiados, pelo menos em certos círculos, que repetem a história do Triunfo do Ocidente por causa da sua mentalidade científica e democrática. ${ }^{21} \mathrm{O}$ livro de Landes, Wealth and Poverty of Nations: Why Some are so Rich and Some so Poor (1998), é especialmente ousado no seu enaltecimento irrestrito da narrativa eurocêntrica. Para dar um pequeno exemplo, escutemos o argumento de Landes para uma interpretação cultural: "Se aprendemos algo da história do desenvolvimento econômico, é que cultura faz toda a diferença (...) o que conta é trabalho, frugalidade, honestidade, paciência, tenacidade." 22

Obviamente, o apelo a uma explicação cultural, que em outras partes do livro não chega a ser tão racista e eurocentrista como no trecho citado, é apresentado nos termos da velha história cultural, com seu conceito monolítico e "essencializado" da cultura. O problema do argumento histórico que fala exatamente o inverso - que as "qualidades" culturais que possibilitavam o sucesso dos europeus eram a avidez, a brutalidade, a barbaridade - é que eles estão trabalhando com a mesma noção determinista e simplificada da cultura. Isto não quer dizer que discordo deles de que a escravidão e o colonialismo contri- 
buíram em boa parte para a "ascensão" do Ocidente, mas este argumento não pode ser baseado numa explicação cultural tão determinista e simplificada. ${ }^{23}$

Outra estratégia para "provincializar a Europa", que está ganhando influência na área da história mundial, nega à cultura qualquer papel significativo no processo de ascensão do Oeste, e é mais ligada aos métodos da political economy, exemplificada nos livros de Kenneth Pomeranz, The Great Divergence: China, Europe and the Making of the Modern World Economy, e Roy Bin Wong, China Transformed: Historical Change and the Limits of the European Experience. $\mathrm{O}$ argumento é principalmente comparativo e conjuntural. Os dois autores, especialistas em história da China, insistem que o nível de desenvolvimento da China até o fim do século XVIII era bastante comparável ao da Europa ocidental, inclusive a Grã Bretanha. ${ }^{24}$ Quer no padrão de vida, na tecnologia, no comércio marítimo, quer na organização estatal e burocrática, as semelhanças eram maiores que as diferenças. Por isso, um observador das duas sociedades no fim daquele século jamais poderia concluir que a Europa Ocidental - e seu primo no Novo Mundo, os Estados Unidos - iria estabelecer sua hegemonia quase inquestionável sobre a economia global no século XIX.

De acordo com esses dois autores, o que explica o "triunfo" inesperado do Ocidente não pode ser a diferença de cultura e de mentalidades, fatores de longo prazo que não explicam uma divergência tão dramática, tão repentina. Em vez das qualidades intrínsecas citadas por Landes, Pomeranz e Bin Wong insistem em contingências, por exemplo, o acesso da Inglaterra aos recursos naturais do Novo Mundo e sua capacidade para exportar seu excesso de população, e conjunturas que permitiram à Europa consolidar sua posição econômica e aproveitar plenamente as novas tecnologias de produção e de poder. ${ }^{25}$

Entre os adeptos da História Mundial, há várias críticas aos argumentos de Pomeranz e Bin Wong, inclusive a que considera que a análise deles meramente transforma um mundo unipolar em um mundo bipolar, China e Europa Ocidental. Mas é o aspecto metodológico dos trabalhos que interessa aqui. Novamente, vale notar que a narrativa ex- 
plicativa deles é totalmente inocente no que diz respeito a referências à história cultural, velha ou nova. É irônico que esses dois livros - tão críticos à historiografia tradicional na sua ênfase à superioridade da cultura ocidental - estejam baseados metodologicamente em abordagens nada inovadoras. Tal fato é compreensível, sobretudo porque os historiadores mais envolvidos na inovação metodológica e nos debates teóricos costumam evitar este tipo de questão macro-histórica. Margaret Jacob, uma historiadora de ciência e adepta da nova história cultural, convidada a comentar o novo livro de Alfred Crosby, que trata da suposta disposição ocidental para a quantificação, assim se expressa:

Para a minha geração de historiadores....as grandes questões da História Ocidental e Mundial se tornaram estranhamente fora de moda. E nenhuma questão era tão grande como a questão de quais fatores possibilitaram a hegemonia ocidental. Aliás, a própria noção da hegemonia ocidental, da dominação de uma boa parte do mundo pelo poder econômico e político do Ocidente de 1800 a 1970, mais ou menos, pode ser considerada tão saturada com sentimentos de raiva e culpa que ela virou um assunto intocável. ${ }^{26}$

Enfim, estamos presenciando uma estranha defasagem entre as preocupações políticas dos historiadores, no sentido de uma ênfase renovada na história mundial, associada a um esforço para repensar as grandes narrativas macro-históricas e as tendências principais, no sentido metodológico, em torno da nova história cultural e sua ênfase nas abordagens antropológicas e micro-históricas. Mas já existem tentativas de vincular uma e outra tendência: num recente ensaio sobre as obras de Pomeranz e Bin Wong, o especialista em história da Índia, David Ludden, principiou a sua argumentação notando que analistas contemporâneos do imperialismo na Índia, escrevendo no início do século XIX, geralmente não costumavam destacar diferenças no nível de "desenvolvimento econômico" (obviamente uma frase anacrônica) entre Inglaterra e Índia; o tema de desigualdade geralmente aparecia em 
termos de diferentes segmentos internos da sociedade, e não de divergências entre colônia e metrópole. Mesmo a grande fome na Índia do século XIX tinha sua contrapartida na Irlanda de 1846-47, com a única diferença sendo que os irlandeses gozavam da opção de imigrar para a América.

Mas a Índia também sofreu com a “Grande Divergência”: em 1818, quando James Mill publicou sua obra-prima sobre a história da Índia Britânica, não havia nenhuma referência à superioridade econômica inglesa. Três décadas depois, Marx podia tratar disso como um fato incontestável. Até este ponto David Ludden está andando no mesmo caminho de Pomeranz e Bin Wong; mas ele tenta ir mais longe, preocupando-se com os discursos de diferença e desigualdade em que a Inglaterra e a Índia desempenhavam papéis distintos na nova ordem mundial, e que cada vez mais associavam a pobreza de um povo à sua suposta incapacidade ou má preparação para a modernidade, em vez de uma falta de sorte ou de condições adequadas. Também surgiu a nova disposição de definir uma economia dentro dos limites da nação; em vez do colonialismo produzindo um sistema pensado como entidade única, surgiu o costume de pensar na Inglaterra como país rico e na Índia como país pobre, cujo povo não tinha (e não terá) a esperança de compartilhar o padrão de vida do cidadão britânico. ${ }^{27}$

Estes insights de David Ludden — sua tentativa de entender a "condição econômica" da Índia moderna em termos de novas linguagens e categorias - atuam como uma ponte para as preocupações dos historiadores que trabalham na área da história e da teoria pós-colonial. Com suas raízes no grupo de estudos subalternos do sul da Ásia, os pesquisadores desta linha definem seu projeto como uma tentativa de repensar a história do ponto de vista do mundo pós-colonial, inclusive da ex-metrópole. Diferentemente da noção de neocolonialismo, um conceito fundamentalmente materialista, esses historiadores reconhecem a luta anticolonial e a independência como momentos e processos significativos, mas ao mesmo tempo reconhecem que a "descolonização" está incompleta num mundo onde o imperialismo, o racismo e o etnocentrismo permanecem de outras formas, tanto na esfera cultu- 
ral como na material, e onde a hibridização da cultura impossibilita um projeto cultural "autônomo", e muito menos "autêntico ${ }^{28}$ ".

Partindo desses pressupostos, esse diversificado grupo de historiadores tem em comum uma forte preocupação com a metanarrativa de progresso que colocava a Europa no centro de todos os processos históricos-uma metanarrativa que, apesar de toda a crítica pós-moderna e da nova história cultural, ainda paira sobre a prática historiográfica, e ainda mais sobre a narrativa histórica que informa o discurso público. No seu prestigiado livro Provincializing Europe, Dipesh Chakrabarty, historiador de origem indiana, mas radicado nos Estados Unidos, no Departamento de História da University of Chicago, apresenta a questão de uma maneira bastante franca: segundo Chakrabarty, ele e os outros historiadores da Ásia - e aqui se pode substituir por África, América Latina — precisam estar atentos à produção dos seus colegas europeus, mas estes não precisam levar em conta a produção intelectual dos historiadores indianos, ou africanos ou latinoamericanos. Mudando para um plano um pouco mais elevado, ele diz a mesma coisa, mas de outra forma: reconhece que existem outras maneiras de representar o indivíduo e a comunidade fora da Europa, mas estes "nunca vão gozar do privilégio de produzir as metanarrativas ou teleologias (pressupondo que não existem narrativas sem, pelo menos, uma teleologia implícita) de nossas histórias". ${ }^{29}$ Para Chakrabarty, o historicismo - e especialmente a "narrativa de transição" - sempre acaba se referindo a uma Europa como a fonte originária da modernidade, da nação e, sobretudo, da razão.

É importante notar o que Chakrabarty, apesar de sua crítica da narrativa eurocentrica, não pretende denunciar, grosso modo, o Iluminismo e a Razão. No último parágrafo do livro, ele faz questão de insistir, ainda uma vez, que o projeto de "provincializar a Europa" jamais poderá ser uma simples rejeição do pensamento europeu, um pensamento que ele caracteriza (sem ironia, acho) como "uma herança para todos nós.” Também insiste que a narrativa histórica que coloca a Europa no centro, como eixo de todo o progresso, não pode ser vista como uma simples imposição do imperialismo europeu; pelo con- 
trário, ele cita os nacionalismos do Terceiro Mundo - discursos modernizadores por excelência - como parceiros à altura do Ocidente na divulgação desta narrativa. Portanto, o grande desafio para Chakrabarty - e muitos outros adeptos da teoria pós-colonial - é imaginar um meio de recusar o historicismo, cujo sujeito teórico é sempre a "Europa", sem descartar as categorias de modernidade política associadas à história européia. ${ }^{30}$

Para demonstrar até que ponto é difícil escapar da trama do historicismo, Chakrabarty prefere citar - em vez de obras históricas como a de Landes, aquele que exaltou as virtudes dos europeus na sua explicação sobre a ascensão do Ocidente, cujos argumentos são bastante fáceis de refutar - as obras de historiadores por quem ele tem grande admiração. Por exemplo, ele discute o famoso ensaio de Edward Thompson sobre Tempo, Disciplina de Trabalho e Capitalismo Industrial. Neste ensaio, Thompson não só retrata o processo pelo qual o trabalhador inglês fica obrigado a internalizar a disciplina associada a processos industriais, como afirma que o mesmo acontece ou acontecerá com o trabalhador do Terceiro Mundo -a única diferença entre a figura do trabalhador na Inglaterra e aquela da Índia é a passagem do tempo secular/histórico. Neste aspecto, o artigo de Thompson é um excelente exemplo da tendência citada por Chakrabarty: "O moderno continua sendo entendido como uma história que nós já conhecemos, algo que já aconteceu em outro lugar, e que será reproduzido, mecanicamente ou não, com um certo conteúdo local”."

Chakrabarty chega a ser ainda mais crítico com seus próprios colegas da Escola de Estudos Subalternos. Ele cita a apresentação do primeiro número de Subaltern Studies, que começa assim: “É o estudo do fracasso histórico da nação [da Índia] a se realizar plenamente, um fracasso devido a uma burguesia inadequada, tanto como uma classe operária incapaz de conduzir uma vitória decisiva sobre o colonialismo (...) é o estudo deste fracasso que constitui a problemática central da historiografia da Índia colonial. ${ }^{32}$

Embora a grande maioria dos seus colegas hoje não repetiria este discurso do "fracasso", Chakrabarty insiste que a tendência de ler a his- 
tória indiana em termos de algo que falta, de algo incompleto, de algo inadequado continua influindo na narrativa histórica, e garante que a narrativa de transição permanecerá sempre "lamentavelmente incompleta". ${ }^{33}$

Mas qual é a alternativa? No seu livro, há quatro capítulos que investigam aspectos da vida cultural e política indiana, costumes e tradições (alguns deles inventados muito recentemente) que, na sua perspectiva, não podem ser tranqüilamente assimilados por uma narrativa historicista. Ele começa usando a distinção feita pelo historiador Paul Veyne entre "singularidade" e "especificidade". ${ }^{34} \mathrm{O}$ específico é um exemplo de uma tendência geral - ele se presta facilmente a uma narrativa explicativa. Aliás, o exemplo das madonas pretas se encaixa muito bem no conceito de especificidade, porque os significados que elas produziam mudavam ao longo do tempo de uma maneira absolutamente previsível, uma vez que elas eram situadas dentro de uma narrativa de secularização e classificação racial ligada ao nascimento da modernidade. Em vez disso, ele vai atrás de formas de sociabilidade ou práticas culturais que são, a seu ver, singulares — isto é, que resistem à assimilação na narrativa historicista. Esses capítulos são interessantes, mas estão longe de resolver o problema que o próprio Chakrabarty apontou. Enfim, mesmo se aceitarmos que ele está falando de singularidades (e não estou inteiramente convencida disto), o resultado é uma série de fragmentos de cultura que servem para demonstrar que a história indiana não é simplesmente uma variação da narrativa histórica européia. Mas isto não altera em nada o projeto maior do livro — o da provincialização da Europa. Pelo contrário, a perspectiva eurocêntrica tem uma longa tradição de situar elementos da cultura "oriental" fora da narrativa histórica - e neste sentido, o argumento de Chakrabarty às vezes corre o risco de cair, sem querer, num discurso "orientalista", que certamente não representa nenhum desafio à visão eurocêntrica do mundo..$^{35}$

$\mathrm{Na}$ verdade, é difícil, dentro da lógica do livro de Chakrabarty, perceber uma estratégia que abra a possibilidade para a Europa de virar uma província. De certa forma, o autor está duplamente preso na armadilha que criou. Ele aceita plenamente, de início, que a cultura in- 
diana seja híbrida e que não existe a possibilidade de escrever uma narrativa "autônoma" (não-ocidentalizada) da sua história. Segundo ele, "o mesmo cadinho colonial no qual a modernidade bengali se originou assegurava que se tornaria impossível construir uma relação histórica do nascimento desta modernidade sem reproduzir algum aspecto das narrativas européias do sujeito moderno..." ${ }^{36}$ Ainda mais, insiste que toda narrativa histórica, aliás, a própria preocupação com a história - que ele chama de "disciplina racional-secular" - a capacidade de ver o passado como separado do tempo atual, inevitavelmente remete a uma Europa associada à razão e ao progresso. Obviamente, para Chakrabarty não existe a possibilidade de escrever uma narrativa macro-histórica da Índia que possa ser substituída pela narrativa do colonialismo. Ele reforça esta posição com referência a um intelectual indiano, B.R. Ambedkar, da época colonial. Em 1916 Ambedkar, num trabalho apresentado na Columbia University que tratava das práticas da sati - a proibição de um novo casamento para as viúvas - e sobre o casamento de meninas/crianças, lamentou a falta total de estudos históricos dessas práticas que podiam explicar "as causas das suas origens e existência." ${ }^{37}$ Chakrabarty retoma este comentário do venerável intelectual com a óbvia finalidade de mostrar quanto Ambedkar pecou, caindo no grave erro historicista, cedendo à tentação de perguntar e querer saber "por quê"? Concordo com Chakrabarty até certo ponto: qualquer tentativa de abordar esta questão com métodos supostamente "científicos" renderia uma "resposta" pouco esclarecedora. Mas discordo dele quando afirma que tais questões resistem a qualquer "historicidade".

Porém, essa atitude de Chakrabarty não chega a ser comungada por todos os historiadores do pós-colonialismo, e quero terminar esta longa "ruminação historiográfica" com uma breve discussão a respeito de um artigo publicado no volume Beyond the Cultural Turn, que oferece um ponto de vista alternativo. $\mathrm{O}$ autor, Steven Feierman, um respeitado estudioso da história da África, também está envolvido no projeto de "provincializar a Europa", mas ele sugere uma estratégia muito distinta para cumprir esta finalidade. ${ }^{38}$ Como Chakrabarty, Feierman 
começa com uma crítica aos historiadores que tentavam escrever uma história pretendendo recuperar “as vozes autênticas" dos africanos, e cita o crescente consenso entre os historiadores e antropólogos da área, de que a cultura africana é híbrida e isto impossibilita qualquer noção (romantizada ou não) de autenticidade. Então, a busca da autenticidade estaria dando lugar a uma nova história cultural da África, que procura entender a interação complexa e extensiva entre as práticas dominantes (de colonialismo, capitalismo e cristianismo) e as práticas locais definidas como africanas. ${ }^{39}$ Depois de enumerar, com uma certa aprovação, as várias pesquisas nesta linha Feierman muda de tom, e vale a pena citar por completo a seguinte crítica feita por ele:

Estas contribuições inovadoras são fascinantes quando consideradas individualmente, mas elas apresentam um profundo problema de representação histórica quando agregadas numa narrativa histórica regional. Os estudos de objetos de consumo (o de pecado cristão) em um lugar, e depois outro, e mais outro, só podem ser agregados na base da sua relação comum com a pertinente categoria européia; eles não podem ser inseridos numa narrativa africana maior ou mais generalizada. O que é africano inevitavelmente aparece de uma forma que é local e fragmentada, e que não tem nenhuma profundidade além da época da conquista colonial, ou o instante logo antes dela. ${ }^{40}$

Nas palavras das próprias organizadoras da coletânea, "concentrando-se exclusivamente no nível micro-histórico, pode-se simplesmente deixar intocadas todas as narrativas macro-históricas costumeiras do sucesso devastador da conquista colonial e da expansão capitalista". ${ }^{41}$ E, de certa forma, os problemas indicados por Feierman nesta nova historiografia coincidem quase exatamente com os problemas que notei acima na discussão da pesquisa histórica de Chakrabarty. Inspirado nesta crítica, Feierman chega a uma conclusão absolutamente oposta ao do seu colega indiano. Apontando sua própria pesquisa sobre a tradição africana (constantemente reprimida e renovada) da cura pública e coletiva, ele se declara a favor da construção de 
uma macro-história africana que privilegie a história das práticas corporais, que não cabem facilmente numa narrativa européia linear. Diferentemente de Chakrabarty, Feierman acredita que estas práticas, apesar das dificuldades que elas apresentam para a narração histórica, não fogem totalmente da capacidade do historiador de pensar em novas narrativas. Ele admite que qualquer macro-história que resulte desta tentativa será muito problemática-talvez tanto quanto a narrativa hegemônica européia - mas insiste que a única maneira de começar a provincializar a Europa seja a criação de outros pontos de referência que não se definem, no último instante, pela narrativa colonial e hegemônica. ${ }^{42}$ Enfim, Feierman está buscando a saída do dilema pós-colonial na criação de múltiplas narrativas macro-históricas, em vez da rejeição pós-moderna da noção da macro-história.

Não pretendo endossar de forma irrestrita a proposta de Steven Feierman. Acho provável que qualquer esforço para construir uma macro-história africana, ou vai essencializar a africanidade, ou vai minimizar o impacto da cultura européia no processo de construção daquela história. Mas entre a rejeição quase total da narrativa histórica - e especialmente qualquer tentativa de explicar "por quê?" - posição de Chakrabarty - e o otimismo de Feierman com respeito à capacidade da imaginação histórica, fico com Feierman.

A proposta acadêmica de provincializar a Europa surge num momento em que a condição pós-colonial é cada vez mais difícil de ignorar nos próprios países da Europa ocidental, e com algumas especificidades da América do Norte também. A presença de imigrantes do antigo império é cada vez mais acentuada, e os debates sobre a capacidade destas sociedades supostamente "ocidentais" de absorver pessoas de culturas e práticas caraterizadas como não-européias são cada vez mais agitados e acirrados. Por isso, o projeto de provincializar a Europa é, ao mesmo tempo, um discurso definindo o futuro que existe, e uma arma para construir o futuro "que será". Seguindo a narrativa "historicista” européia, o futuro é claro: paulatinamente, essas novas coletividades (indianas, árabes, africanas, caribenhas) irão se assimilando os costumes e valores das sociedades modernas e democráticas do Oci- 
dente, deixando para trás aqueles costumes e valores que não se encaixam perfeitamente numa certa noção de modernidade e de cidadania.

Neste sentido, a narrativa atual continua quase idêntica à narrativa histórica da época colonial. Chakrabarty, ao se referir ao discurso colonial dos ingleses na Índia, cita dois elementos-chave - o discurso do progresso e a questão da "condição da mulher" - elementos que continuam sendo fundamentais no discurso de assimilação da época pós-colonial. Para oferecer um rápido exemplo, quero citar um artigo que apareceu no New York Times a 13 de julho de 2003, tratando de um assassinato por honra de uma moça numa região rural da Turquia. O caso da mulher morta é profundamente trágico, e ela merece toda a nossa simpatia-concordo com Chakrabarty e com sua crítica ao relativismo cultural, concordo que "precisamos de valores universais para produzir leituras críticas de injustiças sociais". ${ }^{43}$ Ao mesmo tempo, é difícil não ficar bastante incomodada com a maneira do repórter do Times apresentar a questão: segundo o artigo, o debate sobre a legislação para combater esses assassinatos em defesa da honra faz parte de um esforço "para resolver uma questão que está sendo discutida há séculos sobre o lugar da Turquia no mundo: ou na Europa ou no Oriente Médio". ${ }^{44}$ Quem poderia duvidar que, nesta frase, a Europa representa "o progresso" e o Oriente Médio, "o atraso"? Enquanto este binômio - e a narrativa histórica que o sustenta - continuar informando as nossas visões de mundo, a Europa continuará resistindo à sua provincialização.

WEINSTEIN, B. History without cause? The new cultural History, the grand narrative and the postcolonial dilemma. História. São Paulo, v. 22, n. 2, pp. 185-210, 2003.

ABSTRACT: This article examines the decline of grand narratives in the North American historiography with the rise of the new cultural history. The influence of cultural anthropology - especially the work of Clifford Geertz - has resulted in a preference for microhistory and the eclip- 
se of causation and explanation. At the same time, many postmodern historians continue to refer (though not explicitly) to a Eurocentric narrative of the transition to modernity. In response, criticism of Eurocentrism - the impulse to "provincialize Europe"- has come from two tendencies. One is the new world history, whose proponents are rethinking the grand narratives but with rather traditional methods. The other is postcolonial theory, exemplified by Dipesh Chakrabarty. This last author, although an incisive critic of Eurocentric historiography, does not manage to offer alternatives because he rejects all "historicist" narratives. In contrast, Steven Feierman, a historian of Africa, insists on the necessity of constructing new grand narratives that will provide new points of reference and a way of exiting from the postcolonial dilemma.

KEYWORDS: microhistory; narratives; postcolonial period.

\section{NOTAS}

${ }^{1}$ Department of History - University of Maryland - College Park - Maryland — 20742-7315 - USA.

${ }^{2}$ Para uma discussão da falta de precisão na distinção entre micro e macroanálise, ver RINGER, F. Ringer, Max Weber on Causal Analysis. History and Theory, n. 41, May 2002, p. 175; sobre narrativa e causas, ver PETERS, J. New Historicism: Postmodern Historiography between Narrativism and Heterology. History and Theory, n. 39, Feb. 2000, pp. 21-38.

${ }^{3}$ BLIGHT, D. W. Race and Reunion: The Civil War in American Memory. Cambridge, MA: Harvard University Press, 2001.

${ }^{4}$ Como mostrarei abaixo, este tipo de "determinismo cultural" não desaparecer inteiramente. Um exemplo é o recente livro de LANDES, D. S. Wealth and Poverty of Nations: Why Some are so Rich and Some so Poor. New York: W.W. Norton, 1998; ainda mais gritante na sua recuperação de velhos conceitos de determinismo cultural é SOWELL, T. Conquests and Cultures: An International History. New York: Basic Books, 1998.

${ }^{5}$ GEERTZ, C. The Interpretation of Cultures: Selected Essays. New York: Basic Books, 1973, p. 14. Minha discussão sobre Geertz e a nova história cultural deve muito aos seguintes trabalhos: BIERNACKI, R. Method and Metaphor after the New Cultural History. In: BONNELL, V.; HUNT, L. (Eds.); Beyond the Cultural Turn Ber- 
keley: Univ. of California Press, 1999, pp. 62-92, e APPLEBY, J.; JACOB, M.; HUNT, L. Telling the Truth About History. New York: W.W. Norton, 1994, ch. 6.

${ }^{6}$ DARNTON, R. The Great Cat Massacre and Other Episodes in French Cultural History. New York: Basic Books, 1984.

${ }^{7}$ Este anúncio apareceu na quarta capa da American Historical Review, v. 107, n. 2, Apr. 2002. Devo notar que é a editora, neste caso a Princeton University Press, que geralmente faz o resumo do livro, normalmente com a aprovação do autor do livro.

${ }^{8}$ Este insight vem do novo historicista Stephen Greenblatt. Ver PETERS, J. Op. cit., p. 38 .

${ }^{9}$ YOUNG, E. V. The Other Rebellion. Stanford: Stanford University Press, 2001.

${ }^{10}$ Ver, por exemplo, GUARDINO, P. Peasants, Politics, and the Formation of Mexico's National State: Guerrero, 1800-1857. Stanford: Stanford University Press, 1996; MALLON, F. E. Peasant and Nation: The Making of Postcolonial Mexico and Peru. Berkeley: University of California Press, 1995.

${ }^{11}$ SCHEER, M. From Majesty to Mystery: Change in the Meanings of Black Madonas from the $16^{\text {th }}$ to the $19^{\text {th }}$ Centuries. American Historical Review, v. 107, n. 5, Dec. 2002, pp. 1.412-1.440. O status desta historiadora em relação à comunidade acadêmica norte-americana é questionável. Ela fez a graduação em Stanford University, mas está se formando na pós-graduação na Universidade de Tübingen, na Alemanha. Ao mesmo tempo, ela escreve e publica em inglês, e para um público norte-americano. Enfim, este exemplo reforça o meu senso de que as distinções entre diferentes comunidades acadêmicas estão ficando cada vez mais flexíveis.

${ }^{12}$ Idem. Scheer explicita o seu débito intelectual a Geertz na p. 1.420, nota 25.

${ }^{13}$ Idem, p. 1.440.

${ }^{14}$ Por exemplo, Simon Schama, no seu livro de 1991, Dead Certainties (Unwarranted Speculations), enfrenta os problemas da construção da narrativa histórica, mas acaba suplementado-a com uma narrativa explicitamente ficcional, não para demonstrar as estruturas comuns das duas narrativas, mas porque ele não dispunha de qualquer "texto" que permitisse esse acesso aos discursos dos participantes do crime sendo investigado.

${ }^{15}$ CHARTIER, R. The Cultural Origins of the French Revolution. Durham, NC: Duke University Press, 1991, pp. 2 e 5. Seguindo Foucault, Chartier rejeita qualquer narrativa que prefigure o evento nas suas causas, insistindo que a palavra "origens" quer dizer "reconhecer as mudanças nas crenças e sensibilidades, que podiam fazer uma rápida e profunda destruição da antiga ordem política e social decifrável e aceitável. “Neste sentido, atribuir “origens culturais” à Revolução Francesa de 
maneira alguma significa estabelecer as causas da Revolução... Ver, do mesmo autor, The Chimera of the Origin: Archeology, Cultural History and The French Revolution. In: GOLDSTEIN, J. (ed). Foucault and the Writing of History. Oxford: Blackwell, 1994, pp. 167-186.

${ }^{16}$ Ver, por exemplo, BONNELL, V.; HUNT, L. Introduction. In: Op. cit., pp. 1-32; e o debate sobre este volume na American Historical Review, v. 107, n. 5, Dec. 2002, pp. 1.475-1.520, e especialmente a contribuição de HANDLER, R. Cultural Theory in History Today, pp. 1.512-1.520.

${ }^{17}$ Há uma produção enorme de livros didáticos nesta área, mas a produção de livros "monográficos" é ainda pequena. Uma importante exceção é o livro de BENTON, L. Law and Colonial Cultures: Legal Regimes in World History, 1400-1900. Cambridge: Cambridge University Press, 2002; ver, também, DIAMOND, J. Guns, Germs and Steel: The Fates of Human Societie.s New York, W.W. Norton \& Co., 1997. Existe uma revista inteiramente dedicada ao tema da história mundial, World History, uma World History Association, e um prêmio anual para o melhor livro na área de World History.

${ }^{18}$ Um grupo de historiadores indianos cunhou o termo "estudos subalternos" explicitamente inspirados em Gramsci - para se opor ao que consideravam "uma visão colonialista e elitista" sobre a história da Índia. Seus textos tiveram repercussão no mundo acadêmico dos Estados Unidos, ganhando espaço especialmente entre aqueles que estudavam as sociedades "periféricas", assim como temáticas ligados às mulheres, às minorias, aos despossuídos, aos exilados.

${ }^{19}$ CHAKRABARTY, D. Provincializing Europe: Postcolonial Thought and Historical Difference. Princeton: Princeton University Press, 2000.

${ }^{20}$ Ver, por exemplo, o livro de BLAUT, J. M. Blaut. The Colonizer's Model: Geographical Diffusionism and Eurocentric History. New York, Guilford Press, 1993, e FRANK, A. G. ReOrient: Global Economy in the Asian Age Berkeley: University of California Press, 1998, os dois citados em MOKYR, J. Eurocentricity Triumphant. American Historcial Review, v. 104, n. 4, Oct. 1999, pp. 1.241-1.246.

${ }^{21}$ CROSBY, A. W. The Measure of Reality: Quantification and Western Society, 12501600. Cambridge, Cambridge University Press, 1997; LANDES, D. S. Op. cit.

${ }^{22}$ LANDES, D. S. Op. cit, p. 516.

${ }^{23}$ Claro que o debate sobre a "contribuição" de escravidão e exploração colonial à Revolução Industrial é antigo; começa com a obra de Lenin e continua com o debate sobre a "tese" de Eric Williams. Nunca houve consenso sobre este assunto, mesmo nas fileiras marxistas: historiadores da "escola inglesa", e o historiador da escravidão Eugene Genovese, por exemplo, insistiram que a escravidão e o colo- 
nialismo eram formas antimodernas, que além de não impulsionarem a Revolução Industrial, possivelmente até a retardavam. Mas é interessante notar que hoje a grande maioria dos historiadores de tendência pós-colonial fala do papel fundamental da escravidão e da colonização no surgimento da modernidade como algo transparente e inquestionável. Esta declaração é facilitada pela tendência de tratar essas questões como exclusivamente discursivas. Ver YOUNG, R. J. C. Postcolonialism: An Historical Introduction. Cambridge: Blackwell Publishing, 2001.

${ }^{24}$ POMERANZ, K. The Great Divergence: China, Europe and the Making of the Modern World Economy. Princeton: Princeton University Press, 2000; WONG, R. B. China Transformed: Historical Change and the Limits of the European Experience. Ithaca, NY: Cornell University Press, 1997.

${ }^{25}$ Para um rápido resumo deste debates, ver o fórum: Asia in the World Economy. American Historical Review, v. 107, n. 2, Apr. 2002, pp. 419-480.

${ }^{26}$ JACOB, M. C. Thinking Unfashionable Thoughts, Asking Unfashionable Questions. American Historical Review, v. 105, n. 2, Apr. 2000, p. 494.

${ }^{27}$ LUDDEN, D. Modern Inequality and Early Modernity. American Historical Review, v. 107, n. 2, Apr. 2002, pp. 470-480.

${ }^{28}$ YOUNG, R. J. C. Op. cit., pp. 57-69.

${ }^{29}$ CHAKRABARTY, D. Op. cit., p. 37. Com respeito à questão da estrutura teleológica de toda narrativa, Chartier insiste que "História totalmente privada de qualquer tentação teleológica correria o risco de virar uma enumeração infinita de fatos desvinculados," e que "nenhuma consideração de um problema histórico é possível fora do discurso historiográfico que o construiu". CHARTIER, R. Op. cit, p. 7.

${ }^{30}$ CHAKRABARTY, D. Op. cit., pp. 41, 255.

${ }^{31}$ A discussão do trabalho de Thompson está em CHAKRABARTY, D. Op. cit, p. 48; a citação, na p. 39, é da historiadora australiana, Meaghan Morris.

${ }^{32}$ Idem, pp. 31-32.

${ }^{33}$ Idem, p. 40.

${ }^{34}$ Idem, p. 82. A distinção está em VEYNE, P. Writing History: Essays on Epistemology. Middletown, CT: Wesleyan University Press, 1984, p. 56.

${ }^{35}$ Isto também é a base da crítica articulada por Jacques Pouchepadass na sua resenha do Provincializing Europe, na revista History and Theory n. 41, May 2002, pp. 381-391.

${ }^{36}$ CHAKRABARTY, D. Op. cit, p. 148.

${ }^{37}$ Idem, pp. 145-146. 
${ }^{38}$ FEIERMAN, S. Colonizers, Scholars and the Creation of Invisible Histories. IN: BONNELL, V.; HUNT, L. (Eds). Op. cit, pp. 182-216.

${ }^{39}$ Feierman cita, na p. 184, como a maior influência nesta nova historia cultural da África, o trabalho dos antropólogos-históriadores, Jean e Jean Comaroff.

${ }^{40}$ Idem, p. 185.

${ }^{41}$ BONNELL, V; HUNT, L. Introduction. In:__. Op. cit, p. 20.

${ }^{42}$ Um trabalho que tem uma proposta similar no contexto mexicano é BENJAMIN, T. A Time of Reconquest: History, the Maya Revival, and the Zapatista Rebellion in Chiapas. American Historical Review, v. 105, n. 2, Apr. 2000, pp. 417-450.

${ }^{43}$ CHAKRABARTY, D. Op. cit, p. 254.

${ }_{44}$ "Honor Killings" Defy Turkish Efforts to End Them. New York Times, July 13, 2003, p. 3, grifo meu.

Artigo enviado em 07/2003. Aprovado em 09/2003. 